\title{
Soldado, barbero, coleccionista. Testamento del bachiller Joan Enriquez Chuircho. Cuzco, 14 de junio de 1588
}

Soldier, barber, collector. Testament by bachiller Joan Enriquez Chuircho.

Cuzco, June 14, 1588

\section{Gabriela Ramos}

\section{(Q) OpenEdition}

\section{Journals}

\section{Edición electrónica}

URL: http://journals.openedition.org/corpusarchivos/395

DOI: $10.4000 /$ corpusarchivos.395

ISSN: 1853-8037

Editor

Diego Escolar

\section{Referencia electrónica}

Gabriela Ramos, « Soldado, barbero, coleccionista. Testamento del bachiller Joan Enriquez Chuircho.

Cuzco, 14 de junio de 1588 », Corpus [En línea], Vol 3, No 1 | 2013, Publicado el 15 junio 2013,

consultado el 20 abril 2019. URL : http://journals.openedition.org/corpusarchivos/395 ; DOI :

10.4000/corpusarchivos.395

Este documento fue generado automáticamente el 20 abril 2019.

Licencia Creative Commons: Atribución-NoComercial 2.5 Argentina (CC BY-NC 2.5 AR) 


\section{Soldado, barbero, coleccionista. Testamento del bachiller Joan Enriquez Chuircho. Cuzco, 14 de junio de $1588^{1}$}

Soldier, barber, collector. Testament by bachiller Joan Enriquez Chuircho. Cuzco, June 14, 1588

\section{Gabriela Ramos}

\section{NOTA DEL EDITOR}

Fecha de recepción del original: 10-04-2013

Fecha de aceptación para publicación: 14-05-2013

1 En los años que rodearon a la conquista española, la población del Cuzco se caracterizó por ser muy diversa. El cronista Pedro de Cieza de León anotó que la ciudad estaba "llena de naciones extranjeras y... peregrinas" (Cieza de León, [1553] 1984: cap. XCIII, p. 339). El cronista no detalla cómo coexistían en el día a día las distintas gentes que residían en la capital imperial. Las breves notas que dejó sugieren que Cuzco no era un crisol étnico. Cada grupo vivía en el sitio que sus gobernantes les había asignado, "guardaban las costumbres de sus padres y andaban al uso de sus tierras" (Cieza de León, [1553] 1984: cap. XCIII, p. 339). Las diferencias se hacían visibles por los distintivos que, siguiendo un mandato de los incas, cada quien debía llevar en la cabeza.

2 Los incas tenían aliados y enemigos: era el resultado inevitable de su política de expansión y conquista que alcanzó grandes extensiones. Entre sus adversarios estaban los guancas, habitantes de la sierra central que estuvieron entre los primeros y más activos pueblos prestos a colaborar con los españoles aportando soldados, guías y vituallas. Un número indeterminado de guerreros guancas debió llegar al Cuzco acompañando a los españoles. Pero no eran los únicos o los primeros en llegar a la región. En la ciudad y sus 
alrededores vivía gente natural de Xauxa [Jauja], a quienes se podía identificar por los distintivos que llevaban, unos "ramales que les cayan por debajo de la barba y los cabellos entrenchados". Algunos de esos guancas afincados en el Cuzco habían llegado años atrás llevados por los mismos incas. Varios de ellos tenían cargos administrativos, ocupaban puestos de autoridad y vivían de manera acomodada.

Leemos en su testamento que Joan Enriquez Chuircho era guanca y había nacido en Xauxa, pero lo que no sabemos es con qué grupo estuvo relacionado: si con los que servían a los incas y estaban ya establecidos en la ciudad y en los cálidos valles vecinos al producirse la conquista, o si estaba más estrechamente ligado con los ejércitos de colaboradores que guiaron a los españoles hasta la capital inca. Dada la fecha del testamento, 1588, si acaso presenció los hechos de la conquista, debió haber sido por entonces muy joven.

4 Como muchos hombres y mujeres que vivieron en esta época, las pistas que Joan Enriquez Chuircho dejó sobre su trayectoria son valiosas, aunque incompletas. No sabemos cómo llegó al Cuzco, qué edad tenía, o qué hechos notables le tocó vivir. Sin embargo, este documento nos permite hacer algunas afirmaciones y conjeturas sobre quién fue y cómo se ganaba la vida. Su testamento ofrece indicios de lo que fue la vida de un forastero en la más importante ciudad andina durante una época de cambios cruciales. El listado de sus pertenencias y propiedades sugiere que nos encontramos ante un hombre cuyo perfil no puede trazarse con una sola línea.

5 Enriquez Chuircho se identificaba como cristiano. No conocemos cuándo ni en qué circunstancias recibió el bautismo, pero su testamento revela que se situaba claramente entre quienes profesaban la religión de los conquistadores, posiblemente desde muy joven. Este es un rasgo que compartió con la mayoría de foráneos que llegaron al Cuzco después de la conquista. He discutido en otra parte algunos gestos que hablan de su identidad cristiana (Ramos, 2010a, pp. 232-233). Aquí quisiera enfocarme en tres rasgos que aparecen del examen de sus bienes: en el ámbito de los saberes, su posible ocupación de barbero; en el de la historia, su probable pasado como soldado, y en la esfera de la memoria, su interés de coleccionista.

\section{Saberes}

Llama la atención que Joan Enriquez Chuircho utilice el título de bachiller. Este no alude a un grado universitario, sino seguramente a su oficio de barbero. En el listado de sus bienes aparecen "un estuche y lancetas de sangrar y bolsa". Enriquez Chuircho debió aprender la técnica del sangrado -utilizada ampliamente en la época para tratar todo tipo de males- de algún español, ya que hasta donde se puede saber, esta técnica no fue utilizada en los Andes $^{2}$. Esto revela dos puntos significativos: en primer lugar el aprendizaje y práctica de un saber proveniente de Europa en fecha bastante temprana. Esto le dio posiblemente un lustre particular a su persona, además de la posibilidad de contacto con un público amplio y seguramente variopinto al que pudo ofrecer sus servicios y demostrar sus conocimientos. En segundo lugar, demuestra el rápido aprendizaje y uso oportuno que hizo este personaje de un decreto del Segundo Concilio Limense, que autorizó el ejercicio de la medicina a los especialistas nativos mediante el otorgamiento de licencias, siempre y cuando no hicieran uso de ritos o prácticas que despertaran sospechas (De la Calancha, [1638] 1974: IV, 2, p. 1248). El oficio de barbero, pese a gozar de escaso reconocimiento social, pudo, mediante la posesión de una licencia 
y seguramente apuntalado con el conocimiento de los saberes curativos indígenas, convertir a este personaje en un hombre notable entre sus pares.

Podría decirse que sus aspiraciones y posicionamiento social están en parte representados en las ropas y muebles de estilo español que aparecen en el listado de sus posesiones: "Un vestido de capa y sayo [casaca o traje] y calzas de paño... Una turca de razo carmesi viejo... Un jubon [una especie de chaleco] con sus mangas de razo carmesi y el cuerpo de ruan...”. Enríquez Chuircho debió vestirse a menudo a la usanza española, aunque algunas ropas finas andinas figuran también entre sus pertenencias.

\section{Historia}

El notario que redactó el testamento de Enriquez Chuircho lo describió como "estante" en la ciudad del Cuzco. A primera vista, el término podría sugerir que se encontraba de paso. A otros hombres y mujeres que expidieron sus testamentos por esos mismos años se les describe por lo general como "residentes" en sus parroquias. Posiblemente para efectos de la distribución de la población local y su relación con la doctrina y la vida ritual, Enriquez Chuircho no estaba adscrito a una parroquia. Si un hombre indígena no estuvo incluido en el grupo mayoritario que fue 'reducido' en una parroquia, debemos deducir que su condición era excepcional. Esta presunción se refuerza con el hecho de que solicitó ser sepultado en el convento de Nuestra Señora de la Merced y no en una de las parroquias de la ciudad. Podríamos pensar que estamos ante señales de su cercanía con los conquistadores o sus descendientes: algunos de ellos tuvieron sus entierros en los conventos, particularmente el de La Merced ${ }^{3}$. Otro indicio que nos hace pensar que en el pasado pudo haber sido un soldado estaría representado por las armas españolas que poseía. Entre sus bienes se cuentan “... dos espadas buenas e una espada vieja y dos puñales e una partezana e una asta de lanza con su hierro...”. Una mirada a las propiedades que figuran en su testamento ofrece más señales de la situación privilegiada que disfrutaba. Enriquez Chuircho tenía tierras situadas a diversas distancias de la ciudad, incluido Yucay, un hermoso y próspero valle cercano al Cuzco donde los gobernantes incas tuvieron casas y huertas. Allí, era dueño de algunas chacras de maíz. En otros parajes, tenía sembradíos de tubérculos y, en tierras más distantes y cálidas, era también propietario de parcelas donde cosechaba coca. En todos estos sitios sus sirvientes o yanaconas se encargaban de trabajar la tierra y entregarles parte de los productos. En su testamento, Enríquez Chuircho pagó la fidelidad de algunos y reclamó las deudas contraídas por otros. ¿Cómo fue que un foráneo llegara a tener todas esas propiedades? La posibilidad de que se tratase -al menos en parte- de recompensas por alguna actividad militar no parece descabellada. Pese a que las tierras y herramientas de cultivo eran la parte principal de su patrimonio, Enríquez Chuircho prefirió lo que se consideraba como la vida honorable en la ciudad: tenía casa en Cuzco, contaba entre sus vecinos a algunos conquistadores españoles, mestizos y sus descendientes, y encargó a su hijo y heredero que viviera en la ciudad y no en la región productora de coca conocida entonces como Los Andes. 


\section{Memoria}

9 Suele afirmarse que el coleccionismo surgió con la Ilustración, aunque existen suficientes antecedentes que se inician con la llegada de los europeos al Nuevo Mundo y el envío de joyas y objetos curiosos a la corte española (Cabello Carro, 1994). Varios artículos que aparecen entre los bienes de Enríquez Chuircho me llevan a pensar que este personaje posiblemente tuvo un interés que podría describirse como de coleccionista. Por cierto, no se trataría de la actitud del estudioso, pero posiblemente del que guarda un testimonio de su pasado y, también, de quién registra la diversidad social que lo rodea y la encuentra merecedora de atención. Un ejemplo de lo que afirmo son las armas indígenas y los adornos que debieron ser parte del atuendo de un guerrero:

Una cabellera e una uracaua de plumerias y dos gualcangas de la tierra e una aranua de los guancas e un collar de guaquiri e una trompeta de la tierra que llaman guaillaquipa e unas plumas que llaman supatica e una patena de plata que los yndios llaman purapura... ${ }^{4}$

10 Tal vez conservó estos objetos como memoria de su pasado como soldado. Notamos que entre ellos se encontraba un distintivo de su región de procedencia. Parecería que su condición de foráneo pudo haber estimulado su interés por objetos propios del Cuzco. La lectura de muchos testamentos escritos en Cuzco durante este período me permite afirmar que este es el único -o al menos uno de los pocos- que contiene listas de objetos utilitarios de cerámica y madera con sus nombres quechuas. No parece que se trate de un inventario de objetos ordinarios. El cuidado en registrar los nombres originales sugiere que su propietario tuvo interés en ellos en tanto objetos que representaban la vida material de la ciudad o región que lo acogió.

11 Esta hipótesis podría reforzarse si consideramos las prendas y textiles andinos que formaban parte de sus posesiones. Como muchos de sus contemporáneos, Enriquez Chuircho parece haberse interesado en la calidad de los mismos, como también en su diversidad y el prestigio que representaban. Si bien varias de las ropas que lista estaban gastadas ["traídas"], no deja de llamar la atención que su procedencia se anote tan minuciosamente:

[...] tres mantas traidas la una de quicho yacolla y la otra de chumbe y otra de los yungas e una camiseta azul de lana y otra camiseta de caxana y otra manta que llaman guara y un mamachumbe viejo de los Cuzcos [...].

12 En este grupo resalta la camiseta caxana, una prenda muy apreciada, tejida posiblemente con la técnica más elaborada y fibras más finas, conocida como cumbi. En ilustraciones coloniales, el diseño aparece asociado con la vestimenta de guerreros (Ramos, 2010b) .

13 El bachiller Joan Enriquez Chuircho vivió una época de cambios rápidos y drásticos, y se movió al parecer con éxito entre distintas culturas y saberes. Sin pertenecer a la elite del Cuzco, dado que no era de ascendencia inca, tuvo una situación privilegiada que le permitió una vida cómoda, le exigió conformidad con la cultura española y le permitió mirar con cierta distancia y curiosidad el mundo diverso que lo rodeaba. Un universo en parte en formación y en parte también en proceso de extinción. 


\section{Transcripción}

En el nombre de Dios amen. Sepan quantos esta carta de testamento e ultima e postrimera voluntad vieren como yo el bachiller Joan Enrriquez Chuircho yndio guanca natural del valle de Xauxa estante en esta ciudad del Cuzco caveza del Piru estando enfermo del cuerpo e sano en toda mi voluntad entendimiento qual Nuestro Señor fue servido de me dar creiendo como creo todo aquello que cree e tiene la santa madre yglesia romana hago y ordeno mi testamento e ultima voluntad a servicio de Dios nuestro señor y de su bendita y gloriosa madre en la manera siguiente.

Primeramente encomiendo mi anima a Dios nuestro señor que la crio y redimio y el cuerpo a la tierra de donde fue criado.

Yten mando que si falleciere de la enfermedad de que al presente estoy mi cuerpo sea sepultado en la yglesia del monesterio de Nuestra Señora de las Mercedes desta ciudad en la parte y lugar della que a mis albaceas les pareciere y acompañe mi cuerpo el cura y sacristan del ospital de los naturales donde soy parroquiano con cruz alta y con acompañamiento de las cofradias de donde yo soy cofrade y se pague la limosna acostumbrada.

Yten mando quel dia de mi entierro si fuere ora y sino otro dia siguiente se me diga una misa cantada de cuerpo presente y nueve dias siguientes se me digan nueve misas rezadas en el dicho monesterio de Nuestra Señora de las Mercedes cada dia una misa y se pague la limosna acostumbrada.

Mando a las mandas forzosas quatro reales a todas ellas con lo qual las aparto de mis bienes.

Mando al ospital de naturales desta ciudad (borrado) pesos de a ocho reales declaro que no me deven cosa alguna a ninguna persona pero si paresciere dever a algunas personas en cantidad de diez pesos mando se les pague mostrando claridad dello e ynformacion sumaria.

Declaro que tengo los bienes muebles siguientes.

En el valle de Urubamba tengo una barreta y una barretilla de cobre y dos azuelas de hierro y otra de cobre e una paila e un chamelico de cobre y otro azadon gastado y el chamelico mando se venda y las demas herramientas se esten sirviendo dellas para el beneficio de la chacara que tengo en Urubamba.

Tengo en Palpacalla una azuela de cobre e una barretilla de cobre y dos azadones gastados e una payla tres hachas de hierro lo qual mando no se venda y este para el beneficio de la dicha estancia.

Tengo en mi casa seis azuelas de cobre e tres barretillas y otra barretilla de cobre y tres azadones gastados e una payla e un chamelico de cobre.

Yten tengo en Urubamba un cantaro que llaman urpo ${ }^{\mathrm{b}} \mathrm{y}$ otro chamelico.

Yten tengo dos tinajas grandes y dos cantaros.

Yten dos espadas buenas e una espada vieja y dos puñales e una partezana e una asta de lanza con su hierro.

Tengo dos crucifixos el uno de oro en un cofre chiquito.

Un vestido de capa y sayo y calzas de paño.

$\mathrm{Y}$ otro vestido de paño negro.

Un vestido de cordellate viejo.

Una capa de paño pardo viejo.

Una turca de razo carmesi viejo. 
Un jubon con sus mangas de razo carmesi y el cuerpo de ruan.

Tres pares de botas viejas e unas medias viejas traidas de paño verde e quatro sombreros viejos.

Un colchon e quatro mantas de cumbi que llaman Ancalloc que sirve de cama e una delantera y dos frazadas de Castilla la una colorada y la otra blanca.

Dos candeleros de azofar y otro de cobre.

Un jarro de plata chico y un cubilete de plata e tres cucharas de cobre gastados chicos.

Una caxeta pequeña e una escrivanias (sic) dos camisas.

Dos sierras la una pequeña y otra grande.

Una cabellera e una uracaua de plumerias y dos gualcangas ${ }^{\mathrm{d}}$ de la tierra e una aranua de los guancas e un collar de guaquiri e una trompeta de la tierra que llaman guaillaquipa ${ }^{e} \mathrm{e}$ unas plumas que llaman supatica ${ }^{\mathrm{e}} \mathrm{e}$ una patena de plata que los yndios llaman purapurag $\mathrm{e}$ un toldo de algodon algo nuevo y un arado de la tierra.

Un estuche y lancetas de sangrar y bolsa.

Tres azuelas la una de Castilla e mando se de el dicho estuche y lancetas y azuelas a Francisco Enriquez mi nieto.

Diez platos de peltre chicos y otro grande e una taza de peltre.

Dos pares de cocos de plata el uno dorado en parte.

Un par de mates de plata guarnecidos por fuera de cobre.

Un berguejon de hierro.

Quatro pares de mates de madera y dos mecas ${ }^{\mathrm{h}}$ con su puco ${ }^{\mathrm{i}}$ tres mutcas e un par de calloconsas de madera tres pares de cocos y otro par de cocos a medio hazer y dos pares de mates en que beven e uno pintado y el otro blanco y otros dos mates pequeños de bever e un par de antaras de comer cinco chichicas de cobre y dos antaras de cañare y otros dos de chachapoyas.

Yten tengo tres mantas traidas la una de quicho yacolla ${ }^{j}$ la otra de chumbe ${ }^{k}$ y otra de los yungas e una camiseta azul de lana y otra camiseta de caxana ${ }^{1} \mathrm{y}$ otra manta que llaman guara y un mamachumbe viejo de los Cuzcos y otra sobrecama de cumbe colorada vieja.

Nueve platos de varro que llaman guanboro ${ }^{\mathrm{m}}$ otro par de mates de madera de comer e una mutca de palo dos pares de mates que llaman antara otro par de quijos de beber tres ychonas e un tume.

Yten tengo una estancia que llaman Cantambo de sembrar papas y en ella hasta veynte obejas y dos yanaconas por quien pago la tasa (borrado) Pedro chacara e Pedro si quisieren salirse della puedan yrse y dejar la estancia de tierras.

Tengo en Palpacalla una calderete de cobre.

Todos los quales dichos bienes muebles y si mas se hallare que tengo mandado se vendan y de lo procedido dello se me digan de misas y se haga bien por mi anima pagando primero mi entierro y novenario e misas e todo ello se gaste en hazer bien por mi anima.

Lo qual gasten y dispongan e repartan en los monesterios mis albaceas como a ellos les paresciere.

Declaro ansimesmo que tengo una cuja e un cantaro de hierro de Castilla e un brasero de cobre y cinco cajas con sus cerraduras tres mesas cinco bancos dos sillas de cavallo la una gineta una silla de asentar los quales dichos bienes muebles mando como dicho es se vendan para hazer bien por mi anima como dicho es en la clausula antes desta.

Yten declaro que yo thenia dados dos topos de tierra a do dizen Caribamba a Joan Chuichuc mi hijo mando que los dichos dos topos los aya e goze Francisco Enriques mi nieto para siempre el y sus herederos. 
Mando se de a Ysavel Pilco por lo que me a servido un topo de tierra en Caribamba para ella e para sus herederos.

Declaro que soy casado con Catalina Chimbo mi muger y del matrimonio entre nosotros no thenemos hijos algunos ni al tiempo que con ella me casse rescevi dote alguna ni ay bienes multiplicados mando que todos los dias de su vida biva en estas casas mias en que al presente bivo e todas ellas las tenga e posea todos los dias de su vida e no se le quiten ni parte dellas y las goze y biva y more en ellas y en todas ellas y las posea sin alquiler y no les sean quitadas por mis herederos ni otra persona y despues de sus dias y finamiento mando las dichas casas vengan a mis herederos.

Yten mando que se den en cada un año a la dicha Catalina Chumbe (sic) mi muger por todos los dias de su vida quatro cargas de maiz limpio y desgranado e bueno del maiz que se cojiere en mis chacaras e tierras de Caribamba sin que por ella pague cosa alguna y se le den por mis herederos para ayuda a su sustento.

Mando a Ysavel Antamacoc yndia mi criada por lo que me a servido la chacara de sembrar maiz que hasta agora a poseido que yo le tenia dada lo qual goze los dias de su vida y despues dellos quede a Damian yndio e sus herederos.

Yten mando que la dicha Ysavel Antabacoc biva por todos los dias de su vida en la casa donde al presente bive sin que se le quite hasta que muera ni pague alquiler dello.

Yten declaro que tengo unas casas de mi morada que lindan con casas de Mansio Sierra y la calle de Pedro Alonso Carrasco y el rio desta ciudad y casas de Joan Flores y casa de Cristoval de Mesa con su tienda que sale al rio.

Yten tengo una estancia a do dizen Palpacalla con dos buhios grandes y un topo de alfalfar y seis topos de chacara de maiz con sus arboledas de (borroso).

Yten tengo en el valle de Yucai en el pueblo de Urobamba cinco buhios e una casa con su alto e una guerta e cinco topos y medio de chacara de sembrar maiz en que tengo yanaconas que lo benefician.

Yten tengo las tierras de papas que tengo declaradas en la puna llamadas Caritambo que tengo amojonadas y lindan con Catconga y Chupiurco y Ratias y con una acequia y con el cerro de Pitocancha de que tengo titulos.

Yten tengo una chacara de coca en los Andes a do dizen Capehipata de que se cogen diez cestos cada mita poco mas o menos.

Yten tengo veynte topos de tierra de sembrar maiz a do dizen Caribamba.

Mando se de a Ysabel Hama mi hija natural un topo de tierra en las tierras de Caribamba para ella e para sus herederos.

Yten dejo y nombro por mis albaceas testamentarios e cumplidores deste mi testamento y de lo en el declarado a Anton de Gamboa y a Joan Chuychoc mi hijo e a Pedro Naupa a todos tres juntamente e ynsolidum y doy poder e comision cumplida qual se requiere de derecho para todo ello y lo a ello anexo y dependiente e para que en almoneda o fuera della disponga e venda los dichos bienes en la forma que dicha es.

Ansimismo declaro que me deven las cosas siguientes.

Yten me deve Diego Cusi Guaman yndio setenta pesos que pagué por el e un bestido que le di y ciertos cestos de coca que cogió de mi chacara y se me a alzado con ello mando se cobre del.

Yten me deve Alonso Guaman Tua toda la coca que a cojido despues questa en mi chacara que no me acudido con ella mando se cobre del.

Deveme fulano Anton tres pesos.

Deveme Pedro Machacguai dos pesos.

Deveme don Garcia Ayarmaca un peso y medio. 
Deveme don Joan Yamoc tres pesos.

Deveme Pedro Taime diez e ocho pesos de una camiseta y manta que le vendi e otros ocho pesos que le di para comprar azucar y leña mando se cobre de los susodichos y se haga bien por mi anima con todo lo que dellos se cobrare asi cmo mis albaceas lo ordenaren.

Yten por quanto yo vendi a Cristoval de Mesa la casa questa linde a la mia que se sirve por hazia la calle de Pedro Alonso Carrasco como consta por la venta que dello otorgué a que me refiero e me pidio que con mi licencia queria abrir como abrió puerta hazia mi casa por el agua que avia menester para cierto edificio de adobes e podra ser que aviendo yo fallecido quiera adquerir el derecho a ello quiero e mando que luego se cierre la dicha puerta e portillo e que los susodichos se sirvan por su casa puesta ques la suso declarada y como se la vendi.

Yten mando que Anton de Gamboa biva en las casas que vive el e sus hijos e nietos sin alquiler y despues quede a sus herederos y cumplido y pagado este mi testamento y las mandas e legados declarados en mi testamento en el remaniente que quedare e fincare de mis bienes derechos e acciones dexo y nombro por mi universales herederos en todos los dichos mis bienes al dicho don Joan Chuicho mi hijo natural para que los herede con mi bendicion con que en cada año me diga e haga dezir perpetuamente para en todo tiempo de siempre jamas en el monesterio de Nuestra Señora de las Mercedes doze misas rezadas cada un mes una misa por mi anima las quales se digan en el dicho monasterio por los religiosos del e mis alvaceas tengan quenta de que se digan las dichas misas e se pague por ellas la limosna de un patagon de cada una y las dichas misas esten situadas en los dichos mis bienes hasta que mi hijo heredero conpre la dicha renta a razon de catorze mil el millar que este segura para que della se digan las dichas misas y con cargo que mi hijo biva en esta ciudad e no viva en la provincia de los Andes e haga vida con su muger en esta ciudad e viva cristianamente e revoco e doy por ningunos otros qualesquier testamentos que tenga fecho por escripto o de palabra que quiero que no balgan ni el que hize ante Alonso Herrero escrivano .... salvo este mi testamento y las mandas e legados en el declaradas que balga por mi testamento e ultima boluntad y en la mejor manera que de derecho a lugar en testimonio de lo qual lo otorgué ante el notario publico e testigos en esta dicha ciudad del Cuzco a catorze dias del mes de junio e mil e quinientos y ochenta e ocho años siendo testigos Joan Flores e Joan de Rivas e Joan ...y don Pedro Guaman Paucar y don Joan Poma Vilca e Sebastian Marcarco e Lucas Marcarco y el otorgante que conosco no firmó e firmó un testigo y lo declaró por ynterpretacion del dicho don Pedro ynterprete.

Ante mi

Antonio Sanchez

\section{BIBLIOGRAFÍA}

Cabello Carro, Paz (1994). Los inventarios de objetos incas pertenecientes a Carlos V. Estudio de la colección, traducción y transcripción de los documentos. Anales del Museo de América, 2, 33-61. 
Cieza de León, Pedro ([1553] 1984). Crónica del Perú, Primera Parte. Lima: Pontificia Universidad Católica del Perú.

De la Calancha, Antonio ([1638] 1974). Corónica moralizada del orden de San Agustín. Edición de Ignacio Prado Pastor. Lima: Ignacio Prado Pastor (6 vols.).

González Holguín, Diego ([1608] 1952). Vocabulario de la lengua general de todo el Pirú llamada lengua qquichua o del Inca. Lima: Universidad Nacional Mayor de San Marcos.

Jiménez de la Espada, Marcos (1965). Relaciones Geográficas de Indias, Perú. Madrid: Atlas.

Ramos, Gabriela (2010a). Muerte y conversión en los Andes. Lima y Cuzco, 1532-1670. Lima: Instituto de Estudios Peruanos, Instituto Francés de Estudios Andinos y Cooperación Regional Francesa.

Ramos, Gabriela (2010b). Los tejidos y la sociedad colonial andina. Colonial Latin American Review, 19 (1), 115-149.

\section{NOTAS}

1. Archivo Histórico del Cuzco, Protocolos Notariales, siglo XVI, Antonio Sánchez, N.25, 1587-1600, f. 693.

2. En su descripción de la provincia de Huarochirí fechada en 1586, el corregidor Diego Dávila Briceño aseguró haber enseñado la técnica del sangrado a la gente del lugar. Ver "Descripción y relación de la provincia de los Yauyos toda, Anan Yauyos y Lorin Yauyos, hecha por Diego Dávila Brizeño, corregidor de Guarocheri” (Jiménez de la Espada, 1965, pp. 155-165). La referencia está en páginas 158-159.

3. Tal fue el destino de los restos de Diego de Almagro y su hijo (Ramos, 2010a, p. 82).

4. En la transcripción del testamento figuran los términos que he podido identificar utilizando el diccionario del jesuita Diego González Holguín ([1608] 1952).

5. Sobre las camisetas caxana, véase especialmente página 121 (Ramos, 2010b).

\section{NOTAS FINALES}

a. Chhamillcu. Puchero de barro (González Holguín, [1608] 1952, p. 93).

b. Urppu. Cantaro muy grande mayor que ttico (González Holguín, [1608] 1952, p. 357). Tico. Cantarillo mediano de traer agua (Ídem p. 357).

c. Ancallo. Ropa antigua de las mugeres, muy preciada (Ídem p. 25).

d. Huallccancca: Broquel, o rodela, o escudo (Idem p. 173).

e. Huayllaqquepa. La bozina de caracol grande (Ídem p. 192).

f. Ttica. La flor que es plumaje (Ídem p. 340).

g. Pura pura. Pectoral de metal, una plancha grande adorno de guerra en el pecho, o guarda pechos (Ídem p. 297).

h. Micca. Platos chatos (Idem p. 237).

i. Ppuccu. Escudilla (Ídem p. 293). 
j. Yacollca yaccolla. Manta de indio (Ídem p. 362).

k. Cchumpi. Color castaño escuro o alazan o pardo (Ídem p. 121).

1. Kassana uncu. Camiseta axedrezada de cumbiv (Idem p. 137).

m. Huampuru, o anccara. Mate grande como batea (Idem p. 176).

\section{RESÚMENES}

Se presenta aquí el testamento de Joan Enriquez Chuircho, guanca nacido en Xauxa y migrado al Cuzco en fecha desconocida, quien se identifica como cristiano a pesar de no brindar datos sobre cuándo ni en qué circunstancias había recibido el bautismo. Tres rasgos de su identidad toman contornos a partir del examen de sus bienes: en el ámbito de los saberes, su posible ocupación de barbero; en el de la historia, su probable pasado como soldado, y en la esfera de la memoria, su interés de coleccionista.

We present here the testament of Joan Enriquez Chuircho, Guanca born in Xauxa and migrated to Cuzco in an unknown date, who identifies himself as Christian in spite of not providing information about when or in what circumstances had he received his baptism. Three traits of his identity take shape from the examination of his goods: in the field of knowledge, his possible occupation as barber; in the field of history, his probable past as a soldier, and in the sphere of memory, his interest of collector.

\section{ÍNDICE}

Keywords: Guancas, Inkas, Conquest, Healing knowledge, Testament, Cuzco

Palabras claves: Incas, Conquista, Saberes curativos, Testamento

\section{AUTOR}

\section{GABRIELA RAMOS}

Universidad de Cambridge, Reino Unido. Correo electrónico: gr266@cam.ac.uk 